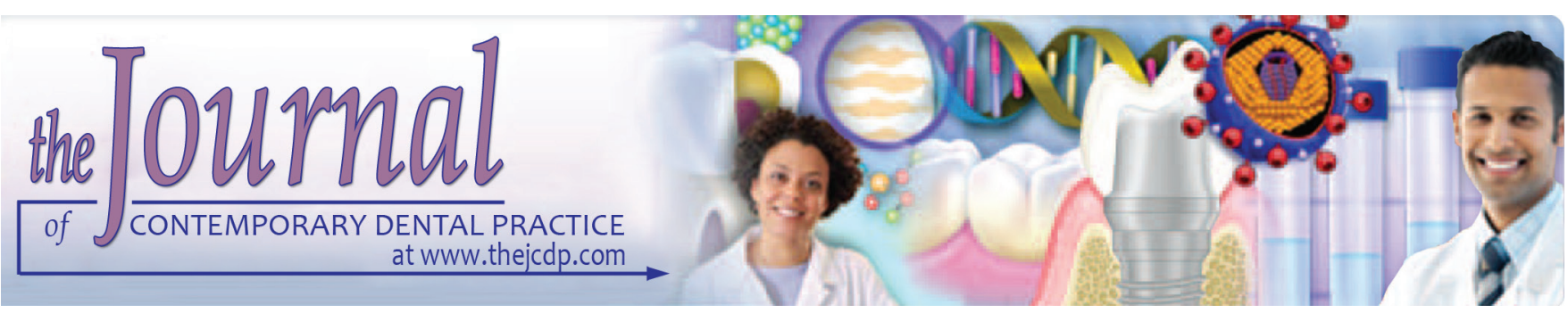

\title{
Evaluation of Clinical Periodontal Indices and Serum Interleukin-27 by One-stage Full-mouth Disinfection and Quadrant Scaling and Root Planing in Periodontitis
}

${ }^{1}$ Amirreza Babaloo, ${ }^{2}$ Mahdi Rahbar, ${ }^{3}$ Zohre Babaloo, ${ }^{4}$ Shima Ghasemi, ${ }^{5}$ Amjad Amini

\begin{abstract}
Introduction: One-stage oral disinfection technique has been developed to prevent cross-contamination between the treated and untreated areas between treatment sessions. Considering the role of inflammatory mediators in periodontitis, this study has been designed to compare the effects of one-stage oral disinfection with quadrant scaling and root planing (Q-SRP) on serum interleukin-27 (IL-27) levels in patients with moderateto-advanced periodontitis.
\end{abstract}

Materials and methods: In this study, two groups were considered. One group was treated with one-stage full-mouth oral disinfection (FMD), while the other group was treated with Q-SRP. In each group, 20 patients with chronic periodontitis were randomly selected based on the inclusion criteria. To evaluate the periodontal status, the clinical parameters of bleeding on probing (BOP), clinical attachment level (CAL), and probing depth (PD) were measured before treatment as well as at 2- and 4-month intervals after treatment. At the same intervals, the immunological index of the study (serum IL-27) was measured by special laboratory kits. The data were analyzed using the Statistical Package for the Social Sciences, version 16

\footnotetext{
${ }^{1,5}$ Department of Periodontics, Dental School, Dental and Periodontal Research Center, Tabriz University of Medical Sciences Tabriz, Islamic Republic of Iran

${ }^{2}$ Department of Operative and Esthetic Dentistry, Dental School Dental and Periodontal Research Center, Tabriz University of Medical Sciences, Tabriz, Islamic Republic of Iran

${ }^{3}$ Department of Immunology, Faculty of Medicine, Tabriz University of Medical Sciences, Tabriz, Islamic Republic of Iran

${ }^{4}$ Department of Prosthodontics, Dental School, Dental and Periodontal Research Center, Tabriz University of Medical Sciences, Tabriz, Islamic Republic of Iran

Corresponding Author: Shima Ghasemi, Department of Prosthodontics, Dental School, Dental and Periodontal Research Center Tabriz University of Medical Sciences, Tabriz Islamic Republic of Iran, Phone: +09143180309, e-mail: dr_ shimaghasemi@yahoo.com
}

(SPSS 16) software. In this study, p-value $<0.05$ was considered statistically significant.

Results: The results of this study indicate that there has been an elevation in the mean of serum IL-27 after treatment in both treatment groups. There is no significant difference between the levels of IL-27 in the FMD group during the study period $(p=0.20)$. All periodontal indices (BOP, CAL, and PD) show clinical improvement in each group $(p<0.001)$. However, no significant difference was observed in the improvement of periodontal indices of CAL and PD $(p<0.05)$.

Conclusion: According to the findings of this study, it can be said that both FMD and Q-SRP improve the periodontal indices and increase the serum level of the inflammatory mediator IL-27 in patients with periodontitis.

Clinical significance: Considering the benefits of the FMD method, such as patient and dentist comfort, systemic effects, and its cost-effectiveness, use of this method is suggested in patients suffering from periodontitis.

Keywords: Chronic periodontitis, Interleukin-27, One-stage full-mouth disinfection, Quadrant scaling and root planning.

How to cite this article: Babaloo A, Rahbar M, Babaloo Z, Ghasemi S, Amini A. Evaluation of Clinical Periodontal Indices and Serum Interleukin-27 by One-stage Full-mouth Disinfection and Quadrant Scaling and Root Planing in Periodontitis. J Contemp Dent Pract 2018;19(8):997-1004.

Source of support: Nil

Conflict of interest: None

\section{INTRODUCTION}

Periodontal diseases are among the most common oral and dental diseases. ${ }^{1}$ Periodontitis is a chronic inflammatory disease in which an inflammatory process destroys the dental supporting structures and bone lysis, and creates periodontal envelopes. ${ }^{2}$ Aggregatibacter actinomycetemcomitans, Tannerella forsythia, and Porphyromonas gingivalis are known as primary microbial agents, but 
several other microorganisms are associated with periodontal diseases. ${ }^{3-6}$ Most of these bacterial species are not only the microbial flora of the subgingival plaque, but are also colonized on mucosal surfaces, the tongue, and tonsil; they are commonly found in saliva. ${ }^{7-11}$ Since the individual's susceptibility to develop such diseases cannot be changed at the clinical level (except for anti-inflammatory drugs), periodontal treatment will focus on reducing or eliminating periodontal pathogens, eliminating the possibility of their recolonization (mainly through the removal of envelopes), and creation of an inappropriate environment (with less anaerobic conditions) for bacterial pathogens. It should be noted that modern therapies are based on nonspecific plaque hypothesis, which also eliminates the useful bacterial species. ${ }^{8-10}$

Several studies have shown that the presence of periodontal pathogens (restoration or colonization after treatment) is associated with the adverse outcomes of periodontal treatment. ${ }^{11-16}$ The usual nonsurgical method for treatment of periodontitis is Q-SRP through multiple sessions. After mechanical removal, the microbial volume of the subgingival plaque decreases to $0.1 \%$ before treatment. ${ }^{8}$ However, after a week, the periodontal envelopes are occupied by the same amount of bacteria, but with less pathogenicity. ${ }^{17,18}$ The proliferation of bacteria in the subgingival region, ${ }^{19}$ junctional epithelium, and envelope epithelium, ${ }^{20}$ or bacteria in the dentinal tubules, posterior surface of the tongue, and tonsils are considered as potential sources of this gingival colonization. ${ }^{21}$ Observations show that plaque along with bacteria in the tongue, oral mucosa, tonsils, and saliva affect the colonization of bacteria in the gingival area after treatment. ${ }^{21}$

Based on the above perspective, Quirynen et $\mathrm{al}^{22}$ suggested a one-stage FMD method, which aims to eliminate or at least suppress all periodontal pathogens from the oropharyngeal area (periodontal envelope, saliva, oral mucosa, and tonsils) within 24 hours using SRP of the entire mouth. In this method, until the periodontal envelope is restored, recolonization of bacteria is delayed through cross-contamination. The above method is a relatively new method and there is a lot of discussion about the effectiveness, rationality, comfort of the patient and the dentist, systemic effects, as well as its cost-effectiveness. Therefore, numerous clinical and paraclinical studies have been conducted with dissimilar results that have made it difficult to judge the method in this field. Some studies did not find any difference between this method and the conventional method of Q-SRP, ${ }^{22-26}$ whereas others emphasized the benefits of the new method. ${ }^{27,28}$ The clinical parameters, including BOP, CAL (clinical adhesion loss), and PD indicate the disease activity, degree of degradation, and progression of the disease. ${ }^{29}$ Several studies, using these parameters, compared FMD method with Q-SRP. One study clearly showed the benefits of FMD as (1) attachment gain; (2) decreased depth of the envelope; and (3) decreased microbiological tendency. ${ }^{29,30}$

Apatzidou and Kinane ${ }^{31}$ also reported the benefits of FMD (0.88 mm attachment) in deep envelopes. Most studies have addressed the clinical and microbiological parameters of this method; only one study reported the immunological effects of this method by suggesting a significant reduction in preinflammatory and inflammatory mediators. ${ }^{31,32}$ Another new and effective method for the diagnosis and determination of periodontal disease activity is the measurement of serum biomarkers. Interleukin-27 is an anti-inflammatory cytokine that inhibits IL-17. ${ }^{33}$ In this study, in addition to clinical parameters, the inflammatory process between the FMD method and Q-SRP was investigated by the measurement of serum IL-27. Furthermore, IL-27 changes were also examined before and after applying two different therapeutic strategies to investigate the periodontal therapeutic effects on the serum levels of inflammatory cytokines, the efficacy of the two above-mentioned treatments in increasing these cytokines, and the disease progression.

\section{MATERIALS AND METHODS}

Twenty patients were randomly assigned to two groups using toss of a coin, after meeting the inclusion and exclusion criteria (the first group was treated by FMD, and the second group was treated using standard method, namely Q-SRP). Blood samples were taken once before treatment, and then at 2- and 4-month intervals after treatment. They were sent to the laboratory for evaluation of biomarkers (IL-27) with specific kits.

\section{Inclusion Criteria}

- Patients with moderate-to-advanced periodontitis.

- Patients aged 25 to 70 years with at least 12 teeth (without considering the third molars and teeth with orthodontic bridges, crowns, and implants) and diagnosis of advanced chronic periodontitis with $30 \%$ presence of teeth with loss of clinical attachment of $3 \mathrm{~mm}$ or more and the presence of radiographic signs of bone resorption.

\section{Exclusion Criteria}

- Systemic diseases (such as diabetes mellitus, cancer, acquired immunodeficiency syndrome, and bone metabolic diseases)

- Diseases that delay wound healing; history of radiotherapy or treatment with immune system suppressor, autoimmune diseases, allergy, and other infectious diseases 
- Pregnancy or lactation

- History of systemic antibiotic use in the last 2 months

- History of continuous use of nonsteroidal antiinflammatory drugs (NSAIDs)

- History of SRP in the previous year

Patients in the control group underwent SRP treatments at 2-week intervals for each quadrant after the blood samples were taken. In the test group, after sampling, the whole mouth was cleaned by an ultrasonic scaling apparatus in two sessions with a time interval of less than 24 hours to reduce the count of pathogenic organisms.

Subgingival rinsing of all envelopes was carried out with $0.2 \%$ chlorhexidine using an insulin syringe to remove all the remaining bacteria. An antiseptic agent $(0.2 \%$ chlorhexidine) was used to brush the tongue's posterior surface to decrease the bacterial load in the area and an antiseptic mouthwash ( $0.2 \%$ chlorhexidine) was used to reduce bacteria in the saliva and on the tonsils.

The variables studied included serum IL-27 levels, as well as the clinical parameters, such as BOP, CAL, and PD, which were measured before starting treatment and then again at 2- and 4-month intervals after treatment. The plaque index was measured by the O'Leary method with the aim of maintaining this index at a value below $10 \%$ (by educating on the plaque control methods) in the 2nd, 4 th, 8 th, 12th, and 16th week intervals after treatment.

The plaque and gingival indexes were considered as control variables and patients with inappropriate cooperation (high plaque index in periodic examinations) were excluded from the study process.

\section{Measurement of the Clinical Parameters}

- Bleeding on probing: Each tooth was probed at four levels of mesial, distal, buccal, and lingual; the probe was slowly drawn and removed with gentle force from the depth of the envelope. We waited for 30 to 60 seconds before examining the bleeding in each area. ${ }^{34}$

- Clinical pocket depth (probe depth): Keeping the probe parallel to the longitudinal axis of the tooth, it enters the depth of the envelope with a force of approx. $25 \mathrm{~g}$, moving around the tooth by the walking method. The PD is recorded in the periodic chart in the four areas of mesiobuccal, midbuccal, distobuccal, and midlingual/midpalatal.

- Clinical attachment level: The result of the difference between the gingival margin and the envelope floor from the cementoenamel junction (CEJ) distance to the gum margin.

It should be noted that the initial examination, patient selection, clinical interventions, patient sampling, and follow-up examinations were conducted at the Periodontics Department and Research Center of Gingival and Oral
Diseases, Tabriz Dental School and para-clinical studies in immunology labs at the Faculty of Medicine of Tabriz in the Applied Pharmaceutical Research Center.

Finally, the data obtained from the study were analyzed by descriptive statistics [mean \pm standard deviation (SD)] and parametric statistical methods including the mean of dependent groups by paired samples t-test and analyzed by SPSS 16 software. The normal distribution of data was assessed by Kolmogorov-Smirnov test and analysis of variance (ANOVA) test was used to compare any probable difference between the tested groups. In this study, $\mathrm{p}$-value less than 0.05 was considered statistically significant.

\section{RESULTS}

In the FMD group, $45 \%$ were male and 55\% were female. In the Q-SRP group, $60 \%$ were male and $40 \%$ were female. Chi-square test did not show any significant difference in the gender frequency between the two groups. The mean age in the FMD group was 43 years and in Q-SRP group was 47.7 years and there was no significant difference in the mean age of the patients $(\mathrm{p}=0.26)$.

The distribution of data was evaluated at three different times (before treatment, then at 2- and 4-month intervals after treatment) by Kolmogorov-Smirnov test. The results showed that all the data in the study had a normal distribution ( $\mathrm{p}>0.05)$.

According to Table 1 and Graph 1, in the FMD group, the mean serum IL-27 was 50.5 before treatment, which increased to 59.3 after 2 months of treatment and reached 59.6 after the 4 -month interval of treatment. The ANOVA (within group) indicated no significant difference in serum IL-27 levels at the studied intervals (before treatment, 2- and 4-month intervals after treatment). In the Q-SRP group, the mean serum IL-27 before treatment was 46.6, which increased to 55.7 in 2 months after treatment and reached 57.4 in 4 months after treatment. The ANOVA (within group) of Q-SRP group showed a significant difference in serum IL-27 levels among intervals (before treatment, 2 , and 4 months after treatment) $(\mathrm{p}<0.05)$. The Scheffe post hoc test was used to evaluate and compare the intervals pairwise in the Q-SRP group. The procedure showed that serum IL-27 levels differed significantly before treatment and 2 months later with a mean difference of $9.1(p<0.05)$. The mean serum IL-27 had a significant difference of $10.8 \%$ before the treatment and 4 months after treatment $(p<0.05)$ as well. There was no significant difference (1.7\%) in the serum IL-17 levels between the 2- and 4-month intervals after treatment.

According to Table 2 and Graph 2, in the FMD group, the mean PD before treatment was 4.1; 2 months after treatment, it was 2.7 , and 4 months after treatment, it was 2.6, which showed a significant difference in PD among 
Table 1: Descriptive and analytical statistics (ANOVA test) for comparing serum IL-27 before and after FMD and Q-SRP

\begin{tabular}{llllll}
\hline Index & Time & Mean \pm SD & Min & Max & $p$-value \\
\hline IL-27 & Baseline & $50.5 \pm 17.16$ & 28 & 84 & $<0.05$ \\
(FMD) & 2 months & $59.3 \pm 18.24$ & 35 & 91 & \\
& 4 months & $59.6 \pm 19.15$ & 32 & 93 & \\
IL-27 & Baseline & $46.6 \pm 15.86$ & 23 & 82 & $<0.05$ \\
(Q-SRP) & 2 months & $55.7 \pm 15.41$ & 36 & 90 & \\
& 4 months & $57.4 \pm 16.87$ & 38 & 99 & \\
\hline
\end{tabular}

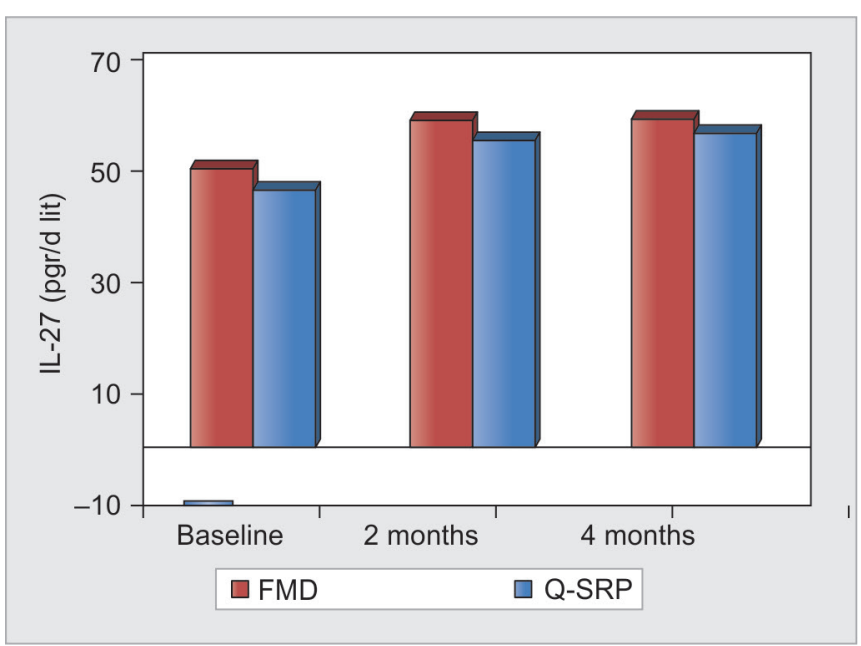

Graph 1: Comparison of serum IL-27 between FMD and Q-SRP before and after treatment

the studied intervals, according to ANOVA test (within group) ( $\mathrm{p}<0.01)$. The Scheffe post hoc test showed that PD had a significant difference before the treatment and 2 months after the treatment $(\mathrm{p}<0.05)$ with mean difference of $1.42 \mathrm{~mm}$. Also, the mean PD had a significant difference before the treatment and 4 months after treatment with a mean difference of $1.5 \mathrm{~mm}(\mathrm{p}<0.05)$. However, there was no significant difference in PD levels between the 2- and 4-month intervals after treatment with only a $0.15 \mathrm{~mm}$ difference in mean values. In the Q-SRP group, the mean PD before treatment was 4.18; 2 months after treatment, it was 2.7, and 4 months after treatment, it was 2.57, which according to ANOVA (within group) is a significant difference in PD among the tested intervals $(\mathrm{p}<0.01)$. Based on the Scheffe post hoc test, PD had a significant difference before treatment and 2 months later with a mean difference of $1.43 \mathrm{~mm}(\mathrm{p}<0.05)$. Also, the mean PD had a significant difference before treatment and 4 months after treatment with mean difference of $1.61 \mathrm{~mm}(\mathrm{p}<0.05)$. The PD levels did not differ significantly between 2 and 4 months after treatment with $0.17 \mathrm{~mm}$ difference $(\mathrm{p}>0.05)$.

According to Table 3 and Graph 3, in the FMD group, the mean CAL before treatment was $4.2 \mathrm{~mm} ; 2$ months after treatment, it was $3.4 \mathrm{~mm}$, and 4 months after treatment, it was $2.78 \mathrm{~mm}$. According to the ANOVA test
Table 2: Descriptive and analytical statistics (ANOVA test) for comparing PD before and after FMD and Q-SRP

\begin{tabular}{llllll}
\hline Index & Time & Mean $\pm S D$ & Min & Max & $p$-value \\
\hline PD (FMD) & Baseline & $4.18 \pm 0.59$ & 3.18 & 5.01 & $<0.05$ \\
& 2 months & $2.76 \pm 0.57$ & 1.32 & 3.61 & \\
& 4 months & $2.60 \pm 0.52$ & 1.29 & 3.58 & \\
PD & Baseline & $4.18 \pm 0.66$ & 2.94 & 5.41 & $<0.05$ \\
(Q-SRP) & 2 months & $2.74 \pm 0.63$ & 1.83 & 4.14 & \\
& 4 months & $2.57 \pm 0.56$ & 1.81 & 3.93 & \\
\hline
\end{tabular}

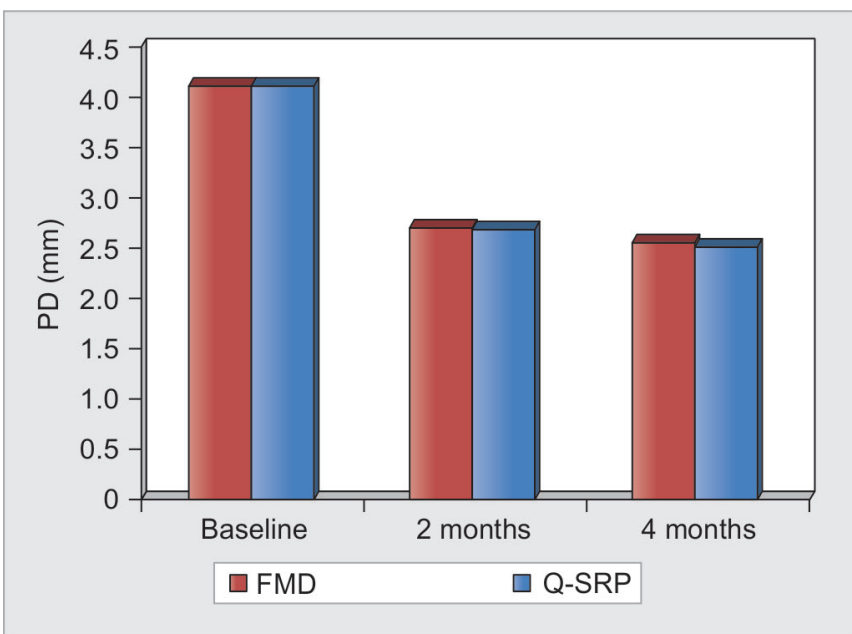

Graph 2: Comparison of PD between FMD and Q-SRP before and after treatment

(within group), there was a significant difference in mean CAL at the tested intervals $(\mathrm{p}<0.01)$. In the $\mathrm{Q}-\mathrm{SRP}$ group, the mean CAL before treatment was $4.2 \mathrm{~mm} ; 2$ months after treatment, it was $3.02 \mathrm{~mm}$, and 4 months after treatment, it was 2.57, which according to the ANOVA test (within group) is a significant difference in CAL among the studied intervals $(p<0.01)$.

According to Table 4 and Graph 4 , in the FMD group, the mean BOP before treatment was $73.8 \% ; 2$ months after treatment, it was $17.9 \%$, and 4 months after treatment, it was $2.7 \%$. According to ANOVA test (within group), there was a significant difference in BOP among the studied intervals $(\mathrm{p}<0.01)$. In the Q-SRP group, the mean BOP before treatment was $72.75 \%$; 2 months after treatment, it was $15.7 \%$, and 4 months after treatment, it was $6.6 \%$, which according to ANOVA test (within group) is a significant difference in BOP among the studied intervals $(\mathrm{p}<0.01)$.

The Scheffe post hoc test in both groups, while examining CAL and BOP indices, shows that (Tables 3, 4 and Graphs 3, 4):

- CAL and BOP before treatment and 2 months later had a significant difference in each group $(\mathrm{p}<0.05)$.

- The mean CAL and BOP before treatment and 4 months after treatment were significantly different in each group $(\mathrm{p}<0.05)$. 
Evaluation of Clinical Periodontal Indices and Serum Interleukin-27

Table 3: Descriptive and analytical statistics (ANOVA test) for comparing CAL before and after FMD and Q-SRP

\begin{tabular}{llllll}
\hline Index & Time & Mean \pm SD & Min & Max & p-value \\
\hline CAL (FMD) & Baseline & $4.20 \pm 0.57$ & 3.18 & 5.01 & $<0.05$ \\
& 2 months & $3.04 \pm 0.59$ & 1.52 & 3.91 & \\
& 4 months & $2.78 \pm 0.54$ & 1.39 & 3.78 & \\
CAL & Baseline & $4.20 \pm 0.67$ & 2.94 & 5.51 & $<0.05$ \\
(Q-SRP) & 2 months & $3.02 \pm 0.62$ & 2.13 & 4.34 & \\
& 4 months & $2.75 \pm 0.56$ & 2.01 & 4.03 & \\
\hline
\end{tabular}

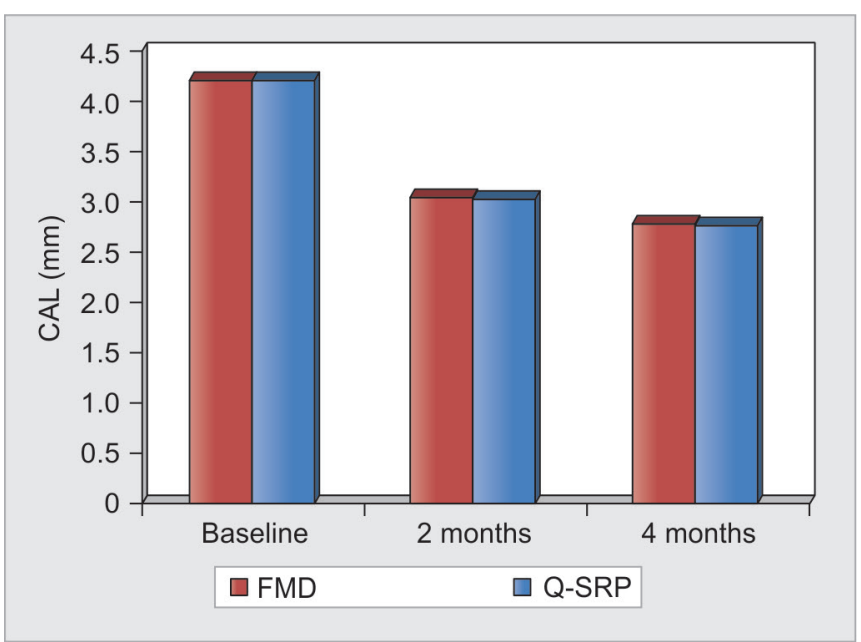

Graph 3: Comparison of CAL between FMD and Q-SRP before and after treatment

- This test showed no significant difference in CAL and $\mathrm{BOP}$ between the 2- and 4-month intervals after treatment in each group $(\mathrm{p}>0.05)$.

According to Table 5 and in accordance with t-test, PD and CAL levels before treatment, and after the 2- and 4-month intervals of treatment did not show significant difference between FMD and Q-SRP groups ( $\mathrm{p}>0.05)$. According to the same table, serum levels of IL-27 before treatment and BOP in the 2- and 4-month intervals after treatment showed a significant difference between FMD and Q-SRP groups $(\mathrm{p}<0.05)$.

\section{DISCUSSION}

Both FMD and Q-SRP are effective methods for the treatment of periodontal diseases, and many studies confirm this claim. ${ }^{28,34-38}$ The purpose of FMD is to remove or at least suppress all periodontal pathogens rapidly from the oropharyngeal area. ${ }^{39,40}$ In this method, bacterial colonization is postponed until better restoration of the periodontal envelope. The above method is a relatively new method and there is a lot of discussion about the effectiveness, rationale, comfort level of patient and dentist, systemic effects, as well as its cost-effectiveness. ${ }^{39,40}$ Therefore, many clinical and paraclinical studies have been conducted with varying results, making it difficult
Table 4: Descriptive and analytical statistics (ANOVA test) for comparing BOP before and after FMD and Q-SRP

\begin{tabular}{lllllc}
\hline Index & Time & Mean $\pm S D$ & Min & Max & $p$-value \\
\hline BOP & Baseline & $73.85 \pm 15.20$ & 32 & 90 & $<0.05$ \\
(FMD) & 2 months & $17.90 \pm 9.32$ & 0 & 34 & \\
& 4 months & $12.75 \pm 13.69$ & 0 & 54 & \\
BOP & Baseline & $72.75 \pm 26.77$ & 2 & 100 & $<0.05$ \\
(Q-SRP) & 2 months & $15.70 \pm 9.29$ & 0 & 40 & \\
& 4 months & $6.60 \pm 5.39$ & 0 & 17 & \\
\hline
\end{tabular}

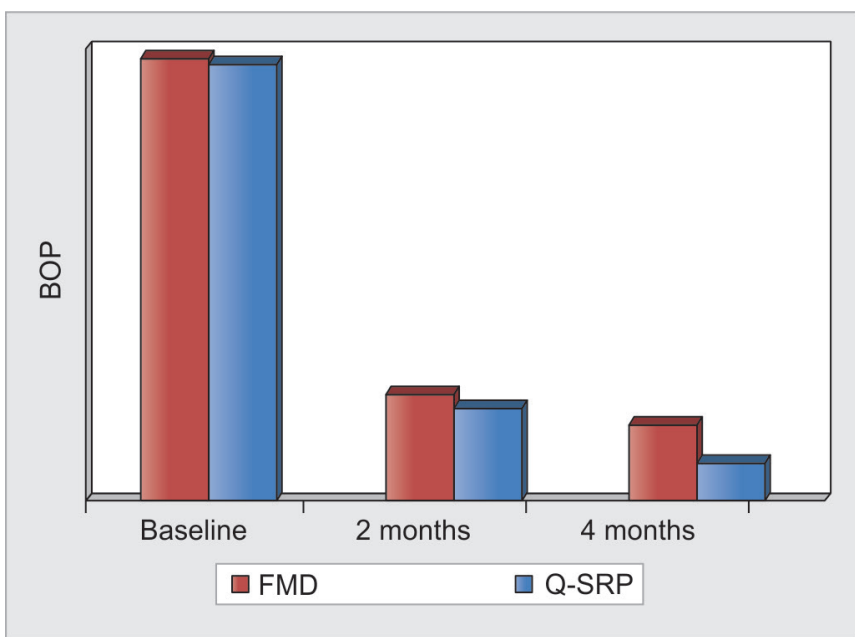

Graph 4: Comparison of BOP between FMD and Q-SRP before and after treatment

to pronounce a clear judgment. ${ }^{39,40}$ A new and effective method for diagnosis of periodontal disease and determination of its activity is by the measurement of serum biomarkers. In this regard, at this center, serum levels of interleukins 17 and 1 were evaluated during the course of scaling treatments and the results indicate a reduction in serum levels of these two proinflammatory interleukins. ${ }^{34}$ Further, to complete these activities and continue the previous research, we investigated the level of IL-27 changes as an anti-inflammatory interleukin during treatment.

Interleukin-27 is a relatively new cytokine that belongs to the IL-12 family. Interleukin-27 is a cytokine derived from antigen-presenting cells, which, in recent years, is a major cytokine in acquired immune responses, and plays its role through the regulation of T-cell-dependent immune responses. The receptor of this cytokine is found in natural killer T cells, B, T, and mast cell, macrophage, dendritic cell, and endothelial cells. ${ }^{40,41}$ According to some studies, IL-27 has a proinflammatory role in some diseases, such as autoimmune diseases, while some studies have defined an anti-inflammatory role for this IL. The existing theory suggests that IL-27 prevents the production of IL-1, IL-6, and IL-17 preinflammatory cytokines, and induces production of anti-inflammatory cytokine IL-10. ${ }^{40,41}$ 
Table 5: Comparison of IL-27, PD, CAL, and BOP in two types of disinfection before and after treatment

\begin{tabular}{|c|c|c|c|c|}
\hline Index & Time & $\begin{array}{l}\text { Treatment } \\
\text { type }\end{array}$ & Mean $\pm S D$ & $p$-value \\
\hline & Baseline & FMD & $5050 \pm 17.16$ & 0.46 \\
\hline & & Q-SRP & $46.60 \pm 15.86$ & \\
\hline \multirow[t]{6}{*}{ IL-27 } & 2 months & FMD & $59.30 \pm 18.24$ & 0.502 \\
\hline & & Q-SRP & $55.70 \pm 15.41$ & \\
\hline & 4 months & FMD & $59.60 \pm 19.15$ & 0.702 \\
\hline & & Q-SRP & $57.40 \pm 16.87$ & \\
\hline & Baseline & FMD & $4.18 \pm 0.59$ & 0.99 \\
\hline & & Q-SRP & $4.18 \pm 0.66$ & \\
\hline \multirow[t]{6}{*}{ PD } & 2 months & FMD & $2.76 \pm 0.57$ & 0.93 \\
\hline & & Q-SRP & $2.74 \pm 0.63$ & \\
\hline & 4 months & FMD & $2.60 \pm 0.52$ & 0.84 \\
\hline & & Q-SRP & $2.57 \pm 0.56$ & \\
\hline & Baseline & FMD & $4.20 \pm 0.57$ & 0.992 \\
\hline & & Q-SRP & $4.20 \pm 0.67$ & \\
\hline \multirow[t]{6}{*}{ CAL } & 2 months & FMD & $3.04 \pm 0.59$ & \\
\hline & & Q-SRP & $3.02 \pm 0.62$ & 0.93 \\
\hline & 4 months & FMD & $2.78 \pm 0.54$ & \\
\hline & & Q-SRP & $2.75 \pm 0.56$ & 0.84 \\
\hline & Baseline & FMD & $69.40 \pm 24.20$ & \\
\hline & & Q-SRP & $76.70 \pm 17.91$ & 0.285 \\
\hline \multirow[t]{6}{*}{ PI } & 2 months & FMD & $12.20 \pm 19.32$ & \\
\hline & & Q-SRP & $10.85 \pm 10.10$ & 0.78 \\
\hline & 4 months & FMD & $5.45 \pm 3.25$ & \\
\hline & & Q-SRP & $5.55 \pm 2.93$ & 0.92 \\
\hline & Baseline & FMD & $73.85 \pm 15.20$ & \\
\hline & & Q-SRP & $72.75 \pm 26.77$ & 0.874 \\
\hline \multirow[t]{4}{*}{ BOP } & 2 months & FMD & $17.90 \pm 9.32$ & \\
\hline & & Q-SRP & $15.70 \pm 9.29$ & 0.46 \\
\hline & 4 months & FMD & $12.75 \pm 13.69$ & \\
\hline & & Q-SRP & $6.6 \pm 5.39$ & 0.07 \\
\hline
\end{tabular}

Most studies on IL-27 have evaluated the clinical and microbiological aspects of this cytokine. However, in this study, in addition to clinical parameters, the immunological effects have been investigated too, suggesting that an increase in IL-27 acts as an anti-inflammatory interleukin.

In the study of Apatzidou et $\mathrm{al}^{23}$ the effects of FMD and quadrant method were evaluated on antibody titers. The results of this study showed that both treatments reduced the antibody titer during the study period (6 months).

In this study, the effect of FMD and Q-SRP on serum levels of IL-27 was compared in patients with moderateto-advanced periodontitis. The results showed that the mean serum IL-27 increased in the 4th month in both methods without a significant difference in mean serum levels of IL-27 between the 2- and 4-month intervals after treatment in any of the groups. In the FMD group, there was no significant difference between the mean serum IL-27 levels of the study intervals. In the Q-SRP group, there was a significant difference between the 2- or 4 month intervals after treatment and before the treatment values. Following the cause of this phenomena, it can be stated that according to previous studies, due to the stimulatory effect of the first session of scaling on production of an immune response (vaccine-like effect), the level of IL-27 increased during these two follow-up periods.

On examining the periodontal indices (BOP, CAL, and PD), clinical improvements were observed in both groups, but there was no significant difference in improvement of CAL and PD periodontal indices between the two groups. In a systematic study, published in 2008 , a very small difference was observed in the clinical parameters, evaluated between the two methods in the treatment of chronic adult periodontitis. ${ }^{38}$ Predin et al ${ }^{42}$ stated in a similar study that both methods led to significant improvement in clinical indices without significant difference between the two groups. Apatzidou and Kinane ${ }^{43}$ and Koshy et a ${ }^{44}$ also obtained similar results in separate studies.

De Genaro Modanese et $\mathrm{al}^{45}$ also examined the immunological and clinical indices of FMD in generalized periodontitis patients and concluded that it significantly reduced the plaque index, pocket depth, and bleeding.

The effect of FMD has been studied in several prospective studies. ${ }^{45-48}$ All of these studies are conducted in accordance with the main standard. In the control group, recolonization of the treated envelopes occurred long before the debridement time of all quadrants (during 6 weeks), and there was inappropriate oral hygiene in the untreated quadrants. In addition, only patients with severe periodontitis with significant amounts of plaquesubgingival and upper gingival plaque-were selected. In contrast, in the test group, debridement of all periodontal envelopes in two consecutive days, along with the use of chlorhexidine, was performed for all the microbial nests, to significantly reduce the amount of bacteria in the oropharynx. ${ }^{46-48}$

All the studies reported better clinical outcomes in the experimental group, including a significant reduction in BOP, CAL, and PD. ${ }^{46-48}$ These clinical results were confirmed by the improvement of clinical indicators in these studies.

The disinfection technique in FMD dramatically reduces the incidence of periodontal abnormal pathogens, especially in the subgingival area and to a lesser extent in the internal oral nests. Several possible explanations were considered for the reported success of FMD. All of the above studies stated that when the possibility of transfer and transduction of intraoral periodontal pathogens decreases, the nonsurgical periodontal treatment will improve. The mechanism of intraoral transfer of these pathogens is still not well defined. However, it seems that the saliva, in which all bacterial species are able to survive, plays an important role in this regard. Changing the direct position of the periodontal pathogens through the flow of 
saliva into periodontal envelopes appears to be unlikely due to the outflow of the subgingival fluid. The indirect impact of any change in the upper gingival plaque that may gradually expand to the subgingival area is a more rational explanation for this phenomenon. In fact, several studies have suggested that at least a portion of the gingival microbiota depends on the presence of upper gingival plaque. ${ }^{49-53}$ However, it should be noted that bacteria can also be displaced by contaminated health supplies and infected dentistry devices that enter the envelope. ${ }^{54}$ Many studies have reported that toothbrushes used daily could be a reservoir for complex periodontal microbiota. ${ }^{55}$

\section{CONCLUSION}

- According to the findings of this study, both FMD and Q-SRP procedures have been successful in improving clinical periodontal indices.

- Both methods increased serum levels of the inflammatory mediator IL-27 during the study period along with the improvement of periodontal clinical indicators.

\section{REFERENCES}

1. Ryan ME. Nonsurgical approaches for the treatment of periodontal diseases. Dent Clin North Am 2005 Jul;49(3):611-636.

2. Hannigan E, O'Connell DP, Hannigan A, Buckley LA. Soluble cell adhesion molecules in gingival crevicular fluid in periodontal health and disease. J Periodontol 2004 Apr;75(4):546-550.

3. American Academy of Periodontology. Proceedings of the 1996 World Workshop in Periodontics. Consensus report. Periodontal diseases: pathogenesis and microbial factors. Ann Periodontol 1996 Nov;1(1):926-932.

4. Slots J, Rams TE. New views on periodontal microbiota in special patient categories. J Clin Periodontol 1991 Jul;18(6):411-420.

5. Socransky SS, Haffajee AD. The bacterial etiology of destructive periodontal disease: current concepts. J Periodontol 1992 Apr;63(4 Suppl):322-331.

6. Wolff L, Dahlén G, Aeppli D. Bacteria as risk markers for periodontitis. J Periodontol 1994 May;65(5 Suppl):498-510.

7. Beikler T,Abdeen G,SchnitzerS, Sälzer S, Ehmke B, Heinecke A, Flemmig TF. Microbiological shifts in intra- and extraoral habitats following mechanical periodontal therapy. J Clin Periodontol 2004 Sep;31(9):777-783.

8. Danser MM, Timmerman MF, van Winkelhoff AJ, van der Velden U. The effect of periodontal treatment on periodontal bacteria on the oral mucous membranes. J Periodontol 1996 May;67(5):478-485.

9. Danser MM, van Winkelhoff AJ, de Graaff J, Loos BG, van der Velden U. Short-term effect of full-mouth extraction on periodontal pathogens colonizing the oral mucous membranes. J Clin Periodontol 1994 Aug;21(7):484-489.

10. Petit MD, van Steenbergen TJ, Timmerman MF, de Graaff J, van der Velden U. Prevalence of periodontitis and suspected periodontal pathogens in families of adult periodontitis patients. J Clin Periodontol 1994 Feb;21(2):76-85.
11. von Troll-Linden B, Saarela M, Mättö J, Alaluusua S, JousimiesSomer H, Asikainen S. Source of suspected periodontal pathogens reemerging after periodontal treatment. J Clin Periodontol 1996 Jun;23(6):601-607.

12. Cugini MA, Haffajee AD, Smith C, Kent RL, Socransky SS. The effect of scaling and root planing on the clinical and microbiological parameters of periodontal diseases: 12-month results. J Clin Periodontol 2000 Jan;27(1):30-36.

13. Haffajee AD, Cugini MA, Dibart S, Smith C, Kent RL, Socransky SS. The effect of SRP on the clinical and microbiological parameters of periodontal diseases. J Clin Periodontol 1997 May;24(5):324-334.

14. Renvert S, Dahlén G, Wikström M. Treatment of periodontal disease based on microbiological diagnosis. Relation between microbiological and clinical parameters during 5 years. J Periodontol 1996 Jun;67(6):562-571.

15. Renvert S, Dahlén G, Wikström M. The clinical and microbiological effects of non-surgical periodontal therapy in smokers and non-smokers. J Clin Periodontol 1998 Feb;25(2):153-157.

16. Socransky SS, Haffajee AD, Cugini MA, Smith C, Kent RL. Microbial complexes in subgingival plaque. J Clin Periodontol 1998 Feb;25(2):134-144.

17. Harper DS, Robinson PJ. Correlation of histometric, microbial, and clinical indicators of periodontal disease status before and after root planing. J Clin Periodontol 1987 Apr;14(4): 190-196.

18. Wade WG, Moran J, Morgan JR, Newcombe R, Addy M. The effects of antimicrobial acrylic strips on the subgingival microflora in chronic periodontitis. J Clin Periodontol 1992 Feb;19(2):127-134.

19. Petersilka GJ, Ehmke B, Flemmig TF. Antimicrobial effects of mechanical debridement. Periodontol 20002002 Jul;28:56-71.

20. Lamont RJ, Yilmaz O. In or out: the invasiveness of oral bacteria. Periodontol2000 2002 Sep;30:61-69.

21. Adriaens PA, De Boever JA, Loesche WJ. Bacterial invasion in root cementum and radicular dentin of periodontally diseased teeth in humans. A reservoir of periodontopathic bacteria. J Periodontol 1988 Apr;59(4):222-230.

22. Quirynen M, Bollen CM, Vandekerckhove BN, Dekeyser C, Papaioannou W, Eyssen H. Full- vs. partial-mouth disinfection in the treatment of periodontal infections: short-term clinical and microbiological observations. J Dent Res 1995 Aug;74(8):1459-1467.

23. Apatzidou DA, Riggio MP, Kinane DF. Quadrant root planing versus same-day full-mouth root planing. 11. Microbiological findings. J Clin Periodontol 2004 Feb;31(2):141-148.

24. Jervoe-Storm PM, Koltzscher M, Falk W, Dörfler A, Jepsen S. Comparison of culture and real-time PCR for detection and quantification of five putative periodontopathogenic bacteria in subgingival plaque samples. J Clin Periodontol 2005 Jul;32(7):778-783.

25. Wennstrom JL, Tomasi C, Bertelle A, Dellasega E. Full-mouth ultrasonic debridement versus quadrant scaling and root planing as an initial approach in the treatment of chronic periodontitis. J Clin Periodontol 2005 Aug;32(8):851-859.

26. Zanatta GM, Bittencourt S, Nociti FH, Sallum EA, Sallum AW, Casati MZ. Periodontal debridement with povidone-iodine in periodontal treatment: short-term clinical and biochemical observations. J Periodontol 2006 Mar;77(3):498-505.

27. Mongardini C, van Steenberghe D, Dekeyser C, Quirynen M. One stage full- versus partial-mouth disinfection in the treatment of chronic adult or generalized early-onset 
penodontitis. I. Long-term clinical observations. J Periodontol 1999 Jun;70(6):632-645.

28. Quirynen M, DeSoete M, Boschmans G, Pauwels M, Coucke W, Teughels W, van Steenberghe D. Benefit of "one-stage fullmouth disinfection" is explained by disinfection and root planing within 24 hours: a randomized controlled trial. J Clin Periodontol 2006 Sep;33(9):639-647.

29. Quirynen M, De Soete M, Dierickx K, van Steenberghe D. The intraoral translocation of periodontopathogens jeopardises the outcome of periodontal therapy. A review of the literature. J Clin Periodontol 2001 Jun;28(6):499-507.

30. Hussain Bokhari SA, Khan AA, Tatakis DN, Azhar M, Hanif M, Izhar M. Non-surgical periodontal therapy lowers serum inflammatory markers: a pilot study. J Periodontol 2009 Oct;:80(10):1574-1580.

31. Apatzidou DA, Kinane DF. Quadrant root planing versus same-day full-mouth root planing. J Clin Periodontol 2004 Mar;31(3):152-159.

32. Teughels W, Dekeyser C, Van Essche M, Quirynen M. Onestage, full-mouth disinfection: fiction or reality?. Periodontol 20002009 Apr;50:39-51.

33. Carl JW, Bai XF. IL27: its roles in the induction and inhibition of inflammation. Int J Clin Exp Pathol 2008;1(2):117-123. .

34. Shirmohammadi A, Babaloo Z, Eskandari A, Purabbas R, Babaloo A. The effects of one-stage full-mouth disinfection and Quadrant-Wise scaling and root planing on serum levels of IL-17 and IL-1 and clinical parameters (A randomized controlled trial study). J Dent (Tehran) 2013 May;10(3):248-255.

35. Zijnge V,Meijer HF, LieMA, TrompJA, Degener JE,Harmsen HJ, Abbas F. The recolonization hypothesis in a full mouth or multiple-session treatment protocol: a blinded, randomized clinical trial. J Clin Periodontol 2010 Jun;37(6):518-525.

36. Swierkot K, Nonnenmacher CI, Mutters R, Flores-de-Jacoby L, Mengel R. Onestage full-mouth disinfection versus quadrant and full-mouth root planing. J Clin Periodontol 2009 Mar;36(3):240-249.

37. Del Peloso Ribeiro E, Bittencourt S, Sallum EA, Nociti FH, Gonc alves RB, Casati MZ. Periodontal debridement as a therapeutic approach for severe chronic periodontitis: a clinical, microbiological and immunological study. J Clin Periodontol 2008 Sep;35(9):789-798.

38. Eberhard J, Jervøe-Storm PM, Needleman I, Worthington $\mathrm{H}$, Jepsen S. Full mouth treatment concepts for chronic periodontitis: a systematic review. J Clin Periodontol 2008 Jul;35(7):591-604.

39. Fang H, Han M, Li QL, Cao CY, Xia R, Zhang ZH. Comparison of full mouth disinfection and quadrant wise scaling in the treatment of adult chronic periodontitis: a systematic review and meta analysis. J Periodontal Res 2016 Aug;51(4):417-430.

40. Mitani A, Niedbala W, Fujimura T, Mogi M, Miyamae S, Higuchi N, Abe A, Hishikawa T, Mizutani M, Ishihara Y, et al. Increased expression of interleukin (IL)-35 and IL-17, but not IL-27, in gingival tissues with chronic periodontitis. J Periodontol 2015 Feb;86(2):301-309.

41. Meka RR, Venkatesha SH, Dudics S, Acharya B, Moudgil KD. IL-27-induced modulation of autoimmunity and its therapeutic potential. Autoimmun Rev 2015 Dec;14(12):1131-1141.
42. Predin T, Djuric M, Nikolic N, Mirnic J, Gusic I, Petrovic D, Milasin J. Clinical and microbiological effects of quadrant versus full-mouth root planing —a randomized study. J Dent Sci 2014 Dec;9(4):400-406.

43. Apatzidou D, Kinane D. Quadrant root planing versus same-day full-mouth root planing. I. Clinical finding. J Clin Periodontol 2004 Feb;31(2):132-140.

44. Koshy G, Kawashima Y, Kiji M,Nitta H,Umeda M,Nagasawa T, Ishikawa I. Effects of single-visit full-mouth ultrasonic debridement versus quadrant-wise ultrasonic debridement. J Clin Periodontol 2005 Jul;32(7):734-743.

45. De Genaro Modanese D, Tiosso-Tamburi R, Furletti de Goes VF, de Cássia Bergamaschi C, Martinez EF, Napimoga MH, Peruzzo DC. Clinical and immunoinflammatory evaluation of one-stage full-mouth ultrasonic debridement as a therapeutic approach for smokers with generalized aggressive periodontitis: a short-term follow-up study. J Periodontol 2016 Sep;87(9):1012-1021.

46. DeSoete M, Mongardini C, Peuwels M, Haffajee A, Socransky S, van Steenberghe D, Quirynen M. One-stage full-mouth disinfection. Long-term microbiological results analyzed by checkerboard DNA-DNA hybridization. J Periodontol 2001 Mar;72(3):374-382.

47. Bollen CM, Vandekerckhove BN, Papaioannou W, Van Eldere J, Quirynen M. Full- versus partial-mouth disinfection in the treatment of periodontal infections. A pilot study: longterm microbiological observations. J Clin Periodontol 1996 Oct;23(10):960-970.

48. Quirynen M, Mongardini C, de Soete M, Pauwels M, Coucke W, van Eldere J, van Steenberghe D. The role of chlorhexidine in the one-stage full-mouth disinfection treatment of patients with advanced adult periodontitis. Long-term clinical and microbiological observations. J Clin Periodontol 2000 Aug;27(8):578-589.

49. Hellstrom MK, Ramberg P, Krok L, Lindhe J. The effect of supragingival plaque control on the subgingival microflora periodontitis. J Clin Periodontol 1996 Oct;23(10): 934-940.

50. Dahlen G, Lindhe J, Sato K, Hanamura H, Okamoto H. The effect of supragingival plaque control on the subgingival microbiota in subjects with periodontal disease. J Clin Periodontol 1992 Nov;19(10):802-809.

51. Listgarten MA. The structure of dental plaque. Periodontol 20001994 Jun;5:52-65.

52. McNabb H, Mombelli A, Lang NP. supragingival cleaning 3 times a week. The microbiological effects in moderately deep pockets. J Clin Periodontol 1992 May;19(5):348-356.

53. Westfelt E, Rylander H, Dahlen G, Lindhe J. The effect of supragingival plaque control on the progression of advanced periodontal disease. J Clin Periodontol 1998 Jul;25(7): 536-541.

54. Waerhaug J. Effect of toothbrushing on subgingival plaque formation. J Periodontol 1981 Jan;52(1):30-34.

55. Quirynen M, de Soete M, Pauwels M, Goossens K, Teughels W, van Eldere J, van Steenberghe D. Bacterial survival rate on tooth- and interdental brushes in relation to the use of toothpaste. J Clin Periodontol 2001 Dec;28(12):1106-1114. 